\title{
Comportamento bioclimático de frangos de corte caipira em piquetes enriquecidos ${ }^{1}$
}

\author{
Marcos J. B. dos Santos ${ }^{2}$, Héliton Pandorfi', Gledson L. P. Almeida ${ }^{4}$, Waldirene B. Morril ${ }^{4}$, Elvira M. R. Pedrosa ${ }^{3}$ \& Cristiane G uiselini $^{3}$
}

\section{RESU MO}

Conduziu-se esta pesquisa com o objetivo de avaliar o efeito do enriquecimento ambiental em sistema de produção para frangos de corte caipira, determinando a influência dos elementos meteorológicos e seu reflexo nos aspectos comportamentais das aves. 0 experimento foi realizado em 87 dias, na Estação Experimental de Pequenos Animais da Universidade Federal Rural de Pernambuco, desenvolvido em quatro módulos de produção e cada módulo dividido em quatro boxes com 10 aves por box, totalizando 160 aves, submetidas aos módulos de produção com acesso a piquete, acesso a piquete com poleiro, acesso a piquete com sombreamento artificial e acesso a piquete com poleiro e sombreamento artificial. 0 delineamento experimental foi inteiramente casualizado em parcelas subdivididas e médias comparadas pelo teste Tukey. 0 módulo de produção com acesso a piquete com poleiro e sombreamento artificial foi aquele que permitiu melhor condicionamento térmico às aves, apresentando valor médio para ental pia de $75,95 \mathrm{~kJ} \mathrm{~kg}^{-1}$, além de promover melhor oportunidade de expressar seus comportamentos naturais e de explorar o ambiente externo ao módulo de produção, potencializando o bem-estar animal.

Palavras-chave: avicultura, comportamento animal, conforto térmico

\section{Bioclimatic behavior of free-range rustic broilers in enriched paddocks}

\begin{abstract}
This study was conducted to evaluate the effect of an enriched environment on the production system of free range rustic broilers, determining the influence of meteorological elements and behavioral responses of the broilers. The experiment was performed during a production cycle of 87 days at the Experimental Station of Small Animals of the Federal Rural University of Pernambuco, conducted in four production modules divided into four boxes with 10 birds per box, totaling 160 birds, subjected to four modules of production: access to paddock, access to paddock with perch, access to paddock with artificial shade, and access to paddock with perch and artificial shade. The experimental design was completely randomized (CRD), in split plots, with the means compared through the Tukey test. The production module with access to the paddock with perch and artificial shade offered the birds the best thermal comfort, having a mean enthalpy value of $75.95 \mathrm{~kJ} \mathrm{~kg}^{-1}$, and were those that had better opportunity to express their natural behavior and to explore the environment outside the production module, thus increasing their well-being.
\end{abstract}

Key words: poultry production, animal behavior, thermal comfort

\footnotetext{
1 Parte da Dissertação de Mestrado do primeiro autor

2 Mestreem EngenhariaAgrícola/UFRPE, Av. Dom M anoel deM edeiro s/n, DoisIrmãos, CEP 52171-900, Recife, PE. Fone: (81) 3088-6099. E-mail: marcoszootecnista@gmail.com

3 DTR/UFRPE. Fone: (81) 3320-6260. E-mails: pandorfi@dtr.ufrpe.br; elvira.pedrosa@dtr.ufrpe.br; guiselini@dtr.ufrpe.br

4 Mestrandos em Engenharia Agrícola/UFRPE. Fone: (81) 3272.0082. E-mail: gledson81@yahoo.com.br; wbbm.2006@hotmail.com
} 


\section{INTRODUÇÃO}

Ao longo dos anos, a avicultura brasileira vem ocupando posição de destaque no mercado agropecuário, com aumento da exportação e do consumo interno, em paralelo a um vertiginoso aumento da tecnologia empregada no País, possibilitando melhor qualidade do produto final. Adicionalmente, existem os efeitos negativos sobre o bem-estar das aves, oriundo da seleção genética para crescimento rápido, tais como as desordens metabólicas, que podem levar à ascite e morte súbita (Bessei, 2006). Consequentemente, a produção de frangos passa a ser alvo de tentativas de melhorias no manejo e alojamento das aves, pressionados por uma parcela da população que busca alimentos mais saudáveis que poluam menos o ambiente e, ao mesmo tempo, promovam o bem-estar animal (Sheppard \& Edge, 2005).

O sistema semi-intensivo de produção de frangos caipira tem conceito diferenciado da produção intensiva, na busca de um sistema de produção menos agressivo ao meio ambiente e às aves. A saúde e o bem-estar animal podem ser afetados positivamente aumentando-se a área de alojamento por animal e garantindo maior liberdade de movimentação (Sundrum, 2001). Em contrapartida, o regime de confinamento total causa estresse intenso (Jones \& Mills, 1999) e tem, como consequência, respostas fisiológicas e comportamentais dos animais (Marin et al., 2001), podendo causar sérios problemas de saúde, produtividade e no bem-estar das aves (Bolis, 2001; Abeyesinghe et al., 2001; Hall, 2001).

O consumo de frango caipira vem, aos poucos, conquistando a preferência do consumidor, por se tratar de um modelo de produção diferenciado (semi-intensivo) de baixa densidade, crescimento lento e abate tardio. Os animais têm acesso direto ao pasto, consumindo insetos e forragens típicas da sua cadeia alimentar. Isto lhe confere textura, cor e sabor diferenciado, e com menos gordura na carcaça (Takahashi et al., 2006); no entanto, há poucas pesquisas com frango caipira no que concerne à sua exigência nutricional, genética, faixa de conforto térmico, etc. Outra questão é determinar o melhor sistema de produção com artifícios que venham promover o bem-estar animal com garantia de boa produtividade.

Neste contexto, a presente pesquisa foi conduzida com o objetivo de se avaliar o efeito do enriquecimento ambiental em sistema de produção para frangos de corte caipira, determinando a influência dos elementos meteorológicos e seu reflexo nos aspectos comportamentais das aves.

\section{MATERIAL E MÉTODOS}

O experimento foi realizado de março a junho de 2008, com duração de 87 dias, na Estação Experimental de Pequenos Animais (EEPAC/UFRPE), apresentando latitude de $7,85^{\circ} \mathrm{S}$, longitude de $35,24^{\circ} \mathrm{W}$ e altitude de $180 \mathrm{~m}$. O clima da região é caracterizado como megatérmico (As’) com precipitação de inverno e estação seca do verão até outono, segundo classificação de Köppen (Pereira et al., 2002). As aves foram alojadas em galpão experimental de produção de frangos de corte até os 30 dias de idade; em seguida, foram transferidas para módulos de produção com acesso a piquetes onde permaneceram por mais 57 dias. Ração e água foram fornecidos ad libitum durante todo o período de criação. Até os 30 dias de idade foi fornecida ração específica para a fase inicial e do $31^{\circ}$ ao $87^{\circ}$ dia do ciclo de produção, dois tipos de dieta, crescimento e terminação, de acordo com o manual da linhagem.

Os módulos de produção eram de alvenaria com piso de concreto, contendo 4 boxes por módulo, com 3,2 m de comprimento por 3,2 $\mathrm{m}$ de largura, pé direito de $3,0 \mathrm{~m}$, beiral de $0,7 \mathrm{~m}$, cobertura com telhas de fibrocimento de $4 \mathrm{~mm}$, laterais com fechamento em alvenaria de 0,4 m de altura e tela metálica, com presença de aberturas em cada um dos boxes que permitiam o acesso das aves ao piquete, das 7 às $17 \mathrm{~h}$, com área de $3 \mathrm{~m}^{2}$ por ave.

As aves foram alojadas em quatro módulos de produção divididos em quatro boxes, totalizando 16 boxes, sendo um box para cada tratamento: módulo de produção com acesso a piquete (T1), módulo de produção com acesso a piquete com poleiro (T2), módulo de produção com acesso a piquete e sombreamento artificial (T3) e módulo de produção com acesso a piquete com poleiro e sombreamento artificial (T4); sendo assim, cada box contou, invariavelmente, com 10 aves e densidade de 10 animais por $\mathrm{m}^{2}$, totalizando 160 aves, machos, linhagem Embrapa-041. Os poleiros foram confeccionados em madeira com dimensões de 1,2 m de altura por 2,0 m de largura em forma de pirâmide, instalados no centro dos piquetes. O sombreamento foi proporcionado pela instalação de malha de sombreamento preta (70\%) recobrindo $60 \%$ da área do piquete.

A pesquisa foi dividida em duas etapas, em função da forma de avaliação dos dados: análise bioclimática e análise comportamental das aves.

A análise bioclimática foi realizada por meio do registro dos dados meteorológicos nos diferentes módulos de produção (T1, T2, T3, T4) e no ambiente externo (EXT). As variáveis meteorológicas registradas foram: temperatura de bulbo seco (Tbs, ${ }^{\circ} \mathrm{C}$ ), temperatura de bulbo úmido (Tbu, ${ }^{\circ} \mathrm{C}$ ), temperatura de globo negro $\left(\mathrm{Tg},{ }^{\circ} \mathrm{C}\right)$ e velocidade do vento $\left(\mathrm{Vv}, \mathrm{m} \mathrm{s}^{-1}\right)$ o que permitiu a caracterização da eficiência térmica nos módulos de produção e no ambiente externo.

Realizaram-se os registros das variáveis meteorológicas em intervalos de 2 h, com medidas às 7, 9, 11, 13, 15 e 17 h, do $31^{\circ}$ ao $87^{\circ}$ dia do ciclo de produção. As variáveis temperatura de bulbo seco (Tbs) e temperatura de bulbo úmido (Tbu) foram registradas por meio de termo-higrômetro da marca Incoterm ${ }^{\circledR}$, escala entre -10 e $50{ }^{\circ} \mathrm{C}$, limite de erro de $\pm 1^{\circ} \mathrm{C}$. Registrou-se a temperatura de globo negro com auxílio de um termômetro comum $\left(-20\right.$ a $\left.110{ }^{\circ} \mathrm{C}\right)$ acoplado a uma esfera oca de polietileno de alta densidade, pintada de preto fosco. Os equipamentos foram instalados no interior de cada módulo de produção, a uma altura de 0,70 m do piso, dispostos no centro geométrico de cada um dos módulos de produção determinando-se, desta forma, o microclima interno aos módulos de produção estudados.

$\mathrm{Na}$ área externa às instalações os termômetros foram instalados a 1,5 m de altura da superfície do solo, no interior 
de um abrigo meteorológico, representando o microclima do local. Fez-se a aquisição dos dados por meio de um termohigrômetro da marca Incoterm ${ }^{\circledR}$ e um termômetro de globo negro.

Para todos os tratamentos e no ambiente externo fez-se o registro da velocidade instantânea do vento $\left(\mathrm{m} \mathrm{s}^{-1}\right)$ nos horários coincidentes com as medidas de temperatura, por meio de um termo-anemômetro da marca AZ Instrumentos ${ }^{\circledR}$, modelo 8908.

Realizou-se a determinação da eficiência térmica das instalações através dos dados referentes às variáveis meteorológicas registradas nos ambientes estudados, em que se determinaram o índice de temperatura de globo e umidade (ITGU) propostos por Buffington et al. (1981), carga térmica radiante $\left(\mathrm{W} \mathrm{m}^{-2}\right)$ proposta por Esmay (1982) e a entalpia (h; kJ kg ar seco-1) proposta por Albright (1990), tendo as seguintes equações:

$$
\mathrm{ITGU}=\mathrm{Tg}+0,36 \mathrm{Tpo}-330,08
$$

em que:

$\mathrm{Tg}$ - temperatura de globo negro (K)

Tpo - temperatura de ponto de orvalho (K)

$$
\begin{gathered}
\mathrm{CTR}=\tau(\mathrm{TMR})^{4} \\
\mathrm{TRM}=100\left\{\left[2,51(\mathrm{Vv})^{0,5}(\mathrm{Tg}-\mathrm{Ts})+\left(\frac{\mathrm{Tg}}{100}\right)^{4}\right]^{0,25}\right\}
\end{gathered}
$$

em que:

TRM - temperatura média radiante

$\mathrm{Vv}$ - velocidade do vento $\left(\mathrm{m} \mathrm{s}^{-1}\right)$

$\mathrm{Tg}$ - temperatura de globo negro (K)

Ts - temperatura de bulbo seco $(\mathrm{K})$

$\tau-5,6710^{-8} \mathrm{~K}^{-4} \mathrm{~W} \mathrm{~m}^{-2}$ (Constante de StefanBoltzmann)

$$
\mathrm{h}=1,006 \mathrm{Tbs}+\mathrm{W}(2501+1,805 \mathrm{Tbs})
$$

em que:

Tbs - temperatura de bulbo seco $\left({ }^{\circ} \mathrm{C}\right)$

W - razão de mistura (kg vapor d'água $\mathrm{kg}$ ar seco ${ }^{-1}$ )

$$
\mathrm{W}=(0,622 \text { ea }) /\left(\mathrm{P}_{\text {atm }}-\mathrm{ea}\right)
$$

em que:

ea - pressão atual de vapor d’água $(\mathrm{kPa})$

$\mathrm{P}_{\mathrm{atm}}$ - pressão atmosférica $(\mathrm{kPa})$

Quando as aves atingiram 30 dias de idade o acesso ao piquete em todos os módulos de criação foi aberto, permitindo a livre passagem das aves para o ambiente externo e, após um período de sete dias de adaptação, deu-se início ao monitoramento dos animais, entre 38 e 87 dias de idade, sendo uma avaliação semanal totalizando 7 avaliações; as avaliações comportamentais foram feitas por observadores posicionados estrategicamente nos módulos de produção e nos piquetes, o que permitiu o monitoramento das aves no período das 7 às $17 \mathrm{~h}$, em intervalos de $2 \mathrm{~h}$ (7, 9, 11, 13, 15 e 17 h) verificando-se a frequência de acesso das aves ao piquete com registro dos comportamentos a cada $5 \mathrm{~min}$.

Para avaliação do comportamento se escolheram, aleatoriamente, seis aves por tratamento, totalizando 24 aves para as observações. As aves selecionadas foram devidamente marcadas com violeta genciana para diferenciação.

As variáveis referentes às reações comportamentais observadas nos tratamentos estudados foram: sentada, comendo, bebendo, forrageando, explorando penas, bicagem não agressiva, bicagem agressiva, bicagem de objetos, movimentos de desconforto, ciscando, banho de areia, parada, poleiro; etograma desenvolvido de acordo com estudos realizados por Rudkin \& Stewart (2003); Alves et al. (2004); Mollenhorst et al. (2005); Barbosa Filho et al. (2007) e Nazareno et al. (2009) o que permitiu verificar os elementos comportamentais que, possivelmente, poderiam ser visualizados nas aves.

O delineamento experimental utilizado para análise das variáveis ambientais foi inteiramente casualizado (DIC) com parcelas subdividas, em que as semanas foram alocadas nas parcelas, os tratamentos e o ambiente externo (EXT) nas subparcelas, adotando-se o programa estatístico Statistical Analysis System (SAS, 1997) com comparação das médias pelo teste de Tukey a nível de $5 \%$ de probabilidade. Os dados referentes às variáveis comportamentais foram submetidos à análise de frequência e percentual do tempo despendido em cada comportamento.

\section{RESULTADOS E DISCUSSÃO}

Observa-se que os módulos de produção e o ambiente externo (T1, T2, T3, T4 e EXT) apresentaram diferenças significativas para temperatura de bulbo seco (Tbs), quando comparados entre si, verificando-se maior temperatura no módulo com acesso a piquete (T1), seguido do módulo com acesso a piquete com poleiro (T2) por não apresentarem artifícios que reduzissem a temperatura interna dos módulos de produção, como se pode constatar nos módulos com acesso a piquetes com sombreamento artificial (T3) e módulo de produção com sombreamento artificial e poleiro (T4) que apresentavam sombreamento artificial em 60\% da área do piquete, alterando o balanço de energia na condição de entorno das instalações, conforme resultados de Silva et al. (2003) apresentando valores da ordem de 29,50; 29,21; 28,46; 28,76 e $28,43^{\circ} \mathrm{C}$, respectivamente (Tabela 1 ).

A variação média da temperatura de bulbo seco (Tbs) não atendeu à condição de conforto térmico das aves ou esteve muito próximo do limite de temperatura crítica superior (TCS). Os tratamentos T3 e T4 foram aqueles que estiveram mais tempo dentro dos limites de 29 e $21^{\circ} \mathrm{C}$, para temperatura crítica superior e inferior, respectivamente, de acordo com os limites estabelecidos por Baêta \& Souza (1997) e Yalcin et al. (1997).

Nota-se efeito significativo para temperatura de globo negro (Tg) nas condições interna e externa aos módulos de produção, verificando-se maior Tg para os módulos T1 e T3 que diferiram do T2 e T4, sendo que o ambiente externo (EXT) apresentou o menor valor ao longo do período anali- 
Tabela 1. Valores médios das variáveis meteorológicas e índices de conforto nos módulos de produção com acesso a piquete (T1), acesso a piquete com poleiro (Poleiro), acesso a piquete com sombreamento artificial (Sombrite), acesso a piquete com poleiro e sombreamento artificial (T4) e ambiente externo (EXT)

\begin{tabular}{|c|c|c|c|c|c|c|}
\hline Módulos & $\begin{array}{l}\text { Tbs } \\
\left({ }^{\circ} \mathrm{C}\right)\end{array}$ & $\begin{array}{l}\mathrm{Tg} \\
\left({ }^{\circ} \mathrm{C}\right)\end{array}$ & $\begin{array}{l}\text { UR } \\
(\%)\end{array}$ & $\begin{array}{c}\mathbf{H} \\
\left(\mathbf{k J ~ k g}^{-1}\right)\end{array}$ & ITGU & $\begin{array}{c}\text { CTR } \\
\left(\mathrm{W} \mathrm{m}^{-2}\right)\end{array}$ \\
\hline $\mathrm{T} 1$ & $29,50 \mathrm{a}$ & $30,09 \mathrm{a}$ & 68,87 e & $76,75 \mathrm{~b}$ & 79,76 a & $472,07 \mathrm{a}$ \\
\hline T2 & $29,21 \mathrm{~b}$ & $29,11 \mathrm{c}$ & $70,32 \mathrm{~d}$ & $76,58 \mathrm{~b}$ & $78,80 \mathrm{c}$ & $473,92 \mathrm{a}$ \\
\hline T3 & $28,46 \mathrm{~d}$ & $29,85 \mathrm{a}$ & $76,43 \mathrm{a}$ & $77,79 \mathrm{a}$ & 79,79 a & $460,14 \mathrm{c}$ \\
\hline T4 & $28,76 \mathrm{c}$ & $29,58 \mathrm{~b}$ & $72,04 \mathrm{c}$ & $75,95 \mathrm{c}$ & $79,24 \mathrm{~b}$ & $465,81 \mathrm{~b}$ \\
\hline EXT & $28,43 \mathrm{~d}$ & $29,07 d$ & $73,18 \mathrm{~b}$ & 75,60 c & 78,73 c & 464,48 b \\
\hline CV\% & 3,47 & 4,29 & 7,28 & 3,62 & 1,68 & 3,26 \\
\hline
\end{tabular}

Na mesma coluna médias seguidas da mesma letra não diferem entre si a $5 \%$ de probabilidade pelo teste de Tukey. $\mathrm{Tbs}=$ temperatura de bulbo seco; $\mathrm{Tg}=$ temperatura de globo negro; $\mathrm{UR}=$ umidade relativa do ar; $\mathrm{h}=$ entalpia e ITGU = índice de temperatura de globo e umidade; $\mathrm{CTR}=$ carga térmica radiante

sado, considerando-se que o estresse térmico ocasionado pela radiação solar difusa é uma parcela significativa às trocas de calor sensível (Pereira et al., 2002); no entanto, não houve diferença ocasionada pelo sombreamento e, sim, pela maior presença das aves no interior dos módulos de produção, corroborando com os resultados encontrados por Furtado et al. (2003) e Silva et al. (2003).

A umidade relativa do ar (UR) apresentou o maior valor médio no módulo de criação T3, seguido pelo ambiente externo (EXT) e pelo módulo com acesso a piquete enriquecido com poleiro e sombra artificial (T4) e a menor no T1. Todos os módulos apresentaram diferenças entre si, determinadas pela adoção da malha de sombreamento que alterou a condição no interior dos módulos de produção (Tabela 1).

As médias da umidade relativa do ar (UR\%) para os módulos de produção T1 e T2 ficaram dentro da faixa recomendada entre 50 e 70\% (Sarmento et al., 2005; Donald, 1998); apesar disto, para os módulos T3 e T4 se nota que os valores de UR\% excederam a faixa recomendada, decorrente do maior aprisionamento de vapor d'água ocasionado pelas malhas de sombreamento o que impedia a livre movimentação do ar e, consequentemente, a dissipação de vapor d’água elevando a umidade do ar.

Em relação à entalpia (h) nota-se que o maior valor médio registrado nos diferentes módulos de criação foi detectado no T3 que diferiu significativamente dos módulos T1 e T2, que também diferiram do T4 e do ambiente externo (EXT), apresentando valores da ordem de 77,79; 76,75; 76,58; 75,95 e 75,60 kJ kg ar seco-1, determinados pela quantidade de energia interna da parcela de ar, pontualmente para mistura de ar seco e vapor d'água, considerando-se a Tbs $\left({ }^{\circ} \mathrm{C}\right)$ e a razão de mistura (kg de vapor d'água $\mathrm{kg}$ de ar seco-1).

Verifica-se que a variação da entalpia nos módulos de produção e no ambiente externo se manteve dentro dos limites de entalpia crítica superior, $81 \mathrm{~kJ} \mathrm{~kg}^{-1}$ e crítica inferior, $42 \mathrm{~kJ} \mathrm{~kg}^{-1}$, indicados por Barbosa Filho et al. (2005) e Alves et al. (2004). O módulo de produção (T4) apresentou as menores médias de entalpia devido ao fato dos animais permanecerem mais tempo fora dos módulos de produção. Moura (2001) afirma que a presença dos animais aumenta a energia dentro dos abrigos.
Para o índice de temperatura de globo e umidade (ITGU) houve efeito significativo entre os módulos de produção e o ambiente externo, em que ocorreu o maior valor médio no módulo de produção T3 e no módulo T1, que diferiram dos módulos T4 e T2; a presença de poleiro estimulou a maior permanência das aves fora dos módulos de produção, o que alterou sensivelmente o índice de conforto das aves (Tabela 1).

A variação do índice de temperatura de globo e umidade (ITGU), obtidos a partir dos valores médios do ITGU nos quatro módulos de criação (T1, T2, T3 e T4) e no ambiente externo (EXT), esteve acima das condições ideais recomendadas para as aves, com limite aceitável de conforto de até 77 (Furtado et al., 2003; Barbosa Filho et al., 2005).

A carga térmica radiante (CTR) apontou influência diante da presença ou não do sombreamento artificial, em que se verifica alteração significativa entre os valores médios apresentados pelos módulos de criação T1 e T2 em relação aos módulos T3 e T4, que ainda assim indicaram diferenças entre si, da ordem de $1,1 \%$.

Com base nos dados médios de Tbs e dos índices ITGU e CTR, não se tem subsídios suficientes para indicar a melhor condição térmica de alojamento para as aves, principalmente quando se leva em consideração o efeito associativo das variáveis estudadas; no entanto, nota-se que, para entalpia (h), o módulo de criação T4 foi o mais adequado devido, provavelmente, à disponibilidade de enriquecimento ambiental, pelo uso de poleiro e sombra artificial na área de piquete.

Verifica-se, na Tabela 2, que as aves que tiveram maior estímulo a permanecerem fora dos abrigos foram aquelas submetidas ao módulo de produção T4, ou seja, em 141 observações isto ocorreu em virtude do efeito aditivo do mecanismo de enriquecimento ambiental e do sombreamento. No módulo de criação T2, notam-se 130 observações da presença de animais no piquete, sinal de que o poleiro pode ser considerado unicamente um referencial para o acesso das aves à área de piquete o que corrobora com Young (2003). As aves submetidas aos módulos de criação T1 e T3 apresentaram menor tempo de permanência nos piquetes, com valores da ordem de 108 e 102 observações, respectivamente; outro fator a se considerar no T1 e T3 é a ausência de objeto físico que servisse de referência como refúgio podendo ter gerado situação de medo e frustração, reduzindo sua atividade de pastejo.

Com referência à porcentagem de tempo em que as aves estiveram comendo, no módulo de produção T1 as aves

Tabela 2. Frequência e porcentagem média das variações comportamentais (dentro e fora) das aves submetidas aos diferentes módulos de produção

\begin{tabular}{cccccc}
\hline $\begin{array}{c}\text { Frequência } \\
\text { Porcentagem (\%) }\end{array}$ & T1 & T2 & T3 & T4 & Total \\
Dentro & 152 & 130 & 158 & 119 & 559 \\
& 14,6 & 12,5 & 15,2 & 11,4 & 53,7 \\
Fora & 108 & 130 & 102 & 141 & 481 \\
& 10,4 & 12,5 & 9,8 & 13,6 & 46,3 \\
\multirow{2}{*}{ Total } & 260 & 260 & 260 & 260 & 1040 \\
& 25,0 & 25,0 & 25,0 & 25,0 & 100,0 \\
\hline
\end{tabular}


apresentaram maior permanência no comedouro durante o período do dia, seguido pelo T4, T3 e T2, com frequência de observação de 75, 74, 73 e 63\%, respectivamente. Os valores correspondentes ao tempo despendido pelas aves alimentando-se retratam a necessidade natural quando dispõem de alimentação nos comedouros, salvo para as aves alojadas no módulo T2, que apresentaram menor frequência de acesso ao comedouro. O motivo que contribuiu para isto foi a presença da malha de sombreamento na área de piquete associada às altas temperaturas no interior do abrigo, o que estimulou a maior permanência das aves no ambiente externo ao módulo de produção (Tabela 3), embora a literatura aponte que o animal se mantém alimentando durante a maior parte do tempo, em razão da ausência de estímulos para a execução de comportamentos diversos (Hughes \& Duncan, 1988).

Observa-se, na Tabela 3, maior frequência de acesso ao bebedouro no módulo de produção T3 coincidindo com o maior valor médio de entalpia no período. Para os autores Sevegnani et al. (2005) e Pereira et al. (2005) o aumento na ingestão de água tem a função de refrigerar o organismo e diminuir a desidratação causada pela perda de calor por via respiratória.

Pela análise de frequência de observações do tempo despendido ao acesso das aves ao bebedouro, é possível dizer que as aves submetidas ao módulo de produção T4 apresentaram condição de conforto superior, comparativamente com as demais condições de alojamento, pois, sob condição de estresse mais acentuado, o consumo de água pelo animal chega a aumentar quase o dobro (Kawabata et al., 2005).

Em condições de estresse calórico o consumo de água está diretamente relacionado ao aumento da demanda de água destinada ao processo de perda de calor por meios evaporativos. Nessas condições, o alto calor específico da água faz com que ela atue como "tampão", fazendo com que a temperatura corporal permaneça constante, frente à flutuação ocorrida na temperatura ambiente (Moura, 2001).

Verifica-se na Tabela 3, que as aves submetidas ao módulo de produção T4 mostraram maior frequência de acesso ao piquete e tempo despendido forrageando, estimuladas sobretudo pelo enriquecimento ambiental, seguido dos T2, T3 e T1, que mostraram frequência de observação da ordem de 49, 44, 38 e 37, respectivamente.

O comportamento de pastejo das aves é um movimento bastante vigoroso, envolvendo atividades fora do módulo de produção, como o ato de bicar os vegetais em busca de alimento. De acordo com Dawkins (1989) o ato de pastejo contribui para a redução de problemas, como o canibalismo. Dawkins (2003) ainda ressalta que o aumento dos níveis de bem-estar em animais que pastejam está associado significativamente ao baixo índice de mortalidade e a condenação de abate.

As aves submetidas ao módulo de produção T3 obtiveram maior valor médio para o ato de ciscar e o menor percentual do tempo despendido ocorreu no módulo T1, confirmando o que Barbosa Filho et al. (2007) descreveram como comportamento considerado característico e natural das aves, caracterizado quando a ave explora seu territó- rio, com os pés e bico sendo que, em condições de altas temperaturas, as aves ciscam menos.

A expressão de bicagem de objetos caracteriza-se quando a ave bica elementos constituintes do local de criação, exceto o material de cama, pastagem e ração. Este comportamento teve registro de ocorrência somente nos módulos de criação T4 e T1 e, ainda assim, muito pouco expressivo. O motivo que pode ter influenciado a baixa incidência deste comportamento foi a possibilidade das aves explorarem seu ambiente de criação. Segundo Mollenhorst et al. (2005), a atitude de bicar telas metálicas ou qualquer outro objeto, pode ser um redirecionamento de comportamento devido à falta ou frustração do acesso a substrato, explorar o ambiente, forragear ou banho de areia.

Bicagem não agressiva é caracterizada pela bicagem em outras aves. De acordo com Abrahanson (1996), a bicagem de penas é considerada um redirecionamento do comportamento de bicagem de alimentos. Durante as observações comportamentais o módulo de produção não propiciou condições de expressão desse comportamento, pelo fato das aves disporem de espaço físico a ser explorado com livre acesso ao piquete.

Com relação à bicagem agressiva, as aves do estudo não apresentaram incidência significativa deste comportamento, relacionado à condição de se estabelecer dominância ou um nível de hierarquia no grupo ou, ainda, pelas condições de estresse provocadas pelo módulo de produção, caracterizando-se por bicadas rápidas e fortes em locais como a crista e outras partes da cabeça (Barbosa Filho et al., 2007).

O comportamento de explorar penas caracteriza-se quando a ave investiga suas próprias penas com o bico ou o faz em relação às penas de outras aves. Neste sentido, nota-se que tal comportamento ocorreu com maior frequência nas aves do módulo de produção T4, pelo fato deste galpão apresentar melhor condição de alojamento.

Segundo Barbosa Filho et al. (2007) o comportamento de explorar penas pode ser considerado comportamento de desconforto, porém Barehan (1976) comenta que a sujeira no empenamento das aves também pode levá-las à maior necessidade de explorar as penas.

O comportamento de banho de areia foi mais evidente no módulo de produção T1, apresentando maior percentual de tempo despendido; trata-se de um comportamento característico e natural das aves, envolvendo uma sequência de ciscar e jogar o material sólido, maravalha e outras fibras vegetais sobre o corpo, além de movimentos rápidos de chacoalhar as penas.

O banho de areia tem efeito comportamental e físico, além de regular o total de camada lipídica das penas e manter a plumagem interna mais solta. $\mathrm{O}$ ato de arrumar penas, tomar banho de areia e outros comportamentos de desconforto, tais como bater asas, ruflar penas e se esticar, são importantes em ambientes de confinamento por manterem a plumagem das aves em boas condições. Os estímulos da luz e da temperatura ambiental podem controlar o horário de realização do banho das aves, bem como sua ocorrência ou não (Hogan \& Boxel, 1993; Appleby \& Hughes, 1991).

Durante a expressão do movimento de desconforto as aves 
que apresentaram maior incidência deste comportamento foram aquelas submetidas ao módulo de produção T2, seguido dos T1, T3 e T4, apresentando valores da ordem de 46, 40, 35 e 31, respectivamente, com a influência de alguns fatores como: temperatura, entalpia e CTR nos módulos de produção.

Durante o estresse térmico, as aves alteraram seu comportamento para auxiliar na manutenção da temperatura corporal e manter-se dentro de limites normais. Ajustes de comportamento podem ocorrer rapidamente e a um custo menor que os ajustes fisiológicos (Pereira et al., 2005).

Com relação à postura sentada das aves, verifica-se que o módulo de produção T2 apresentou maior percentual do tempo despendido, cujo motivo que pode ser levado em consideração é a presença do poleiro, que atraia as aves ao piquete, porém as deixava sujeitas à radiação solar direta, fazendo com que as aves assumissem postura que aumentasse sua superfície de troca de calor com o solo, por contato.

Barbosa Filho et al. (2007) relata que este comportamento pode ser visualizado com facilidade quando as aves se encontram em condições de estresse térmico; uma das explicações seria a necessidade de não se movimentarem muito sob ambientes com altos valores de temperatura visto que o contato com a cama ou o solo, que certamente estaria a

Tabela 3. Variação comportamental das aves submetidas aos diferentes módulo de produção, expressa pela frequência e porcentagem das observações

\begin{tabular}{lrrrrr}
\hline Frequência & \multicolumn{1}{c}{ T1 } & \multicolumn{1}{c}{ T2 } & \multicolumn{1}{c}{ T3 } & \multicolumn{1}{c}{ T4 } & \multicolumn{1}{c}{ Total } \\
Porcentagem (\%) & 75,0 & 63,0 & 73,0 & 74,0 & 285,0 \\
Comendo & 7,1 & 5,8 & 7,1 & 7,1 & 27,1 \\
& 35,0 & 32,0 & 41,0 & 23,0 & 131,0 \\
Bebendo & 3,3 & 3,0 & 3,9 & 2,3 & 12,5 \\
& 37,0 & 44,0 & 38,0 & 49,0 & 168,0 \\
Forrageando & 4,2 & 5,2 & 3,7 & 4,6 & 17,7 \\
& 14,0 & 17,0 & 28,0 & 18,0 & 77,0 \\
Ciscando & 1,3 & 1,5 & 2,7 & 1,7 & 7,2 \\
& 5,0 & 0,0 & 0,0 & 7,0 & 12,0 \\
Bicagem em objetos & 0,4 & 0,0 & 0,0 & 0,6 & 1,0 \\
& 1,0 & 0,0 & 0,0 & 0,0 & 1,0 \\
Bicagem agressiva & 0,1 & 0,0 & 0,0 & 0,0 & 0,1 \\
& 0,0 & 0,0 & 0,0 & 0,0 & 0,0 \\
Bicagem não agressiva & 0,0 & 0,0 & 0,0 & 0,0 & 0,0 \\
& 5,0 & 5,0 & 8,0 & 14,0 & 32,0 \\
Explorando penas & 0,4 & 0,5 & 0,7 & 1,3 & 2,9 \\
& 11,0 & 4,0 & 6,0 & 6,0 & 27,0 \\
Banho de areia & 1,0 & 0,4 & 0,6 & 0,6 & 2,6 \\
& 40,0 & 46,0 & 35,0 & 31,0 & 152,0 \\
Movimento de desconforto & 3,7 & 4,2 & 3,4 & 2,9 & 14,2 \\
& 29,0 & 31,0 & 25,0 & 18,0 & 103,0 \\
Sentadas & 2,7 & 2,8 & 2,4 & 1,8 & 9,7 \\
& 8,0 & 9,0 & 6,0 & 5,0 & 28,0 \\
Parada & 0,8 & 0,8 & 0,5 & 0,6 & 2,7 \\
& 0,0 & 9,0 & 0,0 & 15,0 & 24,0 \\
Poleiro & 0,0 & 0,8 & 0,0 & 1,5 & 2,3 \\
Total & 260 & 260 & 260 & 260 & 1040 \\
& & & & & \\
& & 25,0 & 25,0 & 25,0 & 100,0 \\
\hline
\end{tabular}

uma temperatura inferior à do corpo do animal, favoreceria a troca de calor por condução.

Verificou-se, também, que as aves mantidas nos módulos de produção T1 e T2 foram as que apresentaram maior porcentagem de tempo gasto quando paradas, em relação aos módulos T3 e T4. Então, em condições de estresse térmico é normal que as aves diminuam seu ritmo e passem a ficar paradas por mais tempo, na tentativa de minimizar a produção de calor corporal; trata-se de um mecanismo de defesa das aves uma vez que, ficando paradas, gastam menos energia (Sevegnani et al., 2005; Barbosa Filho et al., 2007).

Nos módulos de produção T2 e T4, em que se dispunha de poleiro verifica-se, em $\mathrm{T} 2$, porcentagem de $0,8 \%$ do uso do poleiro, ao passo que em T4 se nota $1,5 \%$ do tempo despendido das aves no poleiro, evidenciando que as aves se utilizaram deste artifício de enriquecimento ambiental mais no sentido de referencial de proteção que seu uso propriamente dito.

\section{CONCLUSÕES}

1. As variáveis ambientais e os índices de conforto não apresentaram subsídios suficientes para indicar a melhor condição térmica de alojamento para as aves.

2. Para entalpia o módulo de produção com acesso a piquete com poleiro e sombreamento artificial, foi o mais adequado e permitiu melhor condicionamento térmico natural às aves.

3. As aves submetidas ao módulo de produção com acesso a piquete com poleiro e sombreamento artificial foram as que tiveram melhor oportunidade de expressar seus comportamentos naturais e de explorar o ambiente externo ao módulo de produção, potencializando o bem-estar em resposta ao enriquecimento ambiental.

\section{LITERATURA CITADA}

Abeyesinghe, S. M.; Wathes, C. M.; Nicol, C. J. The aversion of broiler chickens to concurrent vibration and thermal stressors. Applied Animal Behaviour Science, v.73, n.3, p.199-215, 2001.

Abrahamsson, P. Furnished cages and aviares for laying hens: effects on production, health and use of facilities. Upsala: Swedish University of Agricultural Sciences, Department of Animal Nutrition and Management, 1996. 234p.

Albright, L. D. Environment control for animals and plants. St. Joseph: American Society of Agricultural Engineers Michigan, 1990. 453p.

Alves, S. P.; Barbosa Filho, J. A. D.; Silva, M. A. N.; Silva, I. J. O.; Bernardi, J. Comparações entre comportamentos de aves poedeiras criadas no sistema de gaiolas e em cama. Revista Brasileira de Ciência Avícola, v.6, n.1, p.140, 2004.

Appleby, M. C.; Hughes, B. O. Welfare of laying hens in cages and alternative systems: environmental, physical and behavioral aspects. World's Poultry Science Journal, v.2, n.47, p.109-128, 1991. 
Baêta, F. C.; Souza, C. F. Ambiência em edificações rurais: Conforto térmico animal. Viçosa: UFV, 1997. 246p.

Barbosa Filho, J. A. D.; Silva, I. J. O.; Silva, M. A. N.; Coelho, A. A. D. Egg quality in layers housed in different production systems and submitted to two environmental conditions. Brazilian Journal of Poultry Science, v.8, n.1, p.23-28, 2005.

Barbosa Filho, J. A. D., Silva, I. J. O.; Silva, M. A. N.; Silva, C. J. M. Avaliação dos comportamentos de aves poedeiras utilizando seqüência de imagens. Engenharia Agrícola, v.27, n.1, p.93-99, 2007.

Barehan, J. R. A comparison of the behaviour and production of laying hens in experimental and conventional battery cages. Applied Animal Ethology, v.2, n.2, p.291-303, 1976.

Bessei, W. Welfare of Broilers: A review. World's Poultry Science Journal, v.62, p.455-466, 2006.

Bolis, D. A. Biosseguridade na criação alternativa de frangos. In: Conferência de Ciência e Tecnologia Avícola: APINCO, 2001. Campinas. Anais... Campinas: APINCO, 2001. p.223-234.

Buffington, D. E.; Colazzo-Arocho, A.; Caton, G. H. Black globe humidity comfort index (BGHI) as comfort equation for dairy cows. Transaction of the ASAE, v.24, n.4, p.711-714, 1981.

Dawkins, M. S. Behaviour as a tool in the assessment of animal welfare. Zoology, v.106, p.383-387, 2003.

Dawkins, M. S. Time budgets in red junglefowl as a baseline for the assessment of welfare of domestic fowl. Applied Animal Behaviour Science, v.24, p.77-80, 1989.

Donald, J. Environmental control options under different climate conditions. World Poultry, v.14, n.11, p.22-27, 1998.

Esmay, M. L. Principles of animal environment. West Port CT: ABI, 1982. 325p.

Furtado, D. A.; Azevedo, P. V. de; Tinôco, I. de F. Análise do conforto térmico em galpões avícolas com diferentes sistemas de acondicionamento. Revista Brasileira de Engenharia Agrícola e Ambiental, v.7, n.3, p.559-564, 2003.

Hall, A. H. The effect of stocking density on the welfare and behaviour of broiler chickens reared commercially. Animal Welfare, v.10, n.1, p.23-40, 2001.

Hogan, J. A.; Boxel, F. van. Casual factors controlling dustbathing in Burmese red Junglefowl: some results and a model. Animal Behaviour, v.46, p.627-635, 1993.

Hughes, B.; Duncan, I. The notion of ethological "need”, models of motivation, and animal welfare. Animal Behavior, v.36, p.1696-707, 1988.

Jones, R. B.; Mills, A. D. Divergent selection for social reinstatement behavior in Japanese quail: Effects on sociality and social discrimination. Poultry Avian Biology Review, v.10, n.4, p.213-223, 1999.

Kawabata, C. Y.; Castro, R. C.; Savastano Júnior, H. Índices de conforto térmico e respostas fisiológicas de bezerros da raça holandesa em bezerreiros individuais com diferentes coberturas. Engenharia Agrícola, v.25, n.3, p.598-607, 2005.

Marin, R. H.; Freytes, P.; Guzman, D.; Jones, R. B. Effects of an acute stressor on fear and on the social reinstatement responses of domestic chicks to agemates and strangers. Applied Animal Behaviour Science, v.71, n.1, p.57-66, 2001.
Mollenhorst, H.; Rodenburg, T. B.; Brokkers, E. A. M.; Koene, P.; Boer, I. J. M. On-farm assessment of laying hen welfare: A comparison of one environment - Based and two animal-based methods. Applied Animal Behaviour Science, v.90, n.3/4, p.277-291, 2005.

Moura, D. J. Ambiência na avicultura de corte. In: Silva, I. J. O. Ambiência na produção de aves em clima tropical. Jaboticabal: SBEA, 2001. p.75-149.

Nazareno, A. C.; Pandorfi, H.; Almeida, G. L. P.; Giongo, P. G.; Pedrosa, E. M. R.; Guiselini, C. Avaliação do conforto térmico para frangos de corte sob regime de criação diferenciado. Revista Brasileira de Engenharia Agrícola e Ambiental, v.13, n.6, p.802-808, 2009.

Pereira, A. R.; Angelocci, L. R.; Sentelhas, P. C. Agrometeorologia: Fundamentos e aplicações práticas. Guaíba: Agropecuária, 2002. 478p.

Pereira, D. F.; Nääs, I. A.; Romanini, C. E. B.; Salgado, D. D.; Pereira, G. O. T. Indicadores de bem-estar baseados em reações comportamentais de matrizes pesadas. Engenharia Agrícola, v.25, n.2, p.308-314, 2005.

Rudkin, C.; Stewart, G. D. Behaviour of hens in cages - a pilot study using video tapes. A Report for the Rural Industries Researsh and Development Corporation, v.40, n.477, p.102, 2003.

Sarmento, L. G. V.; Dantas, R. T.; Furtado, D. A.; Nascimento, J. W. B.; da Silva, J. H. V. Efeito da pintura externa do telhado sobre o ambiente climático e o desempenho de frangos de corte. Agropecuária Técnica, v.26, n.2, p.117-122, 2005.

SAS Institute. Statistical analysis system: Realease 6.08, (software). Cary, 1997. 620p.

Sevegnani, K. B.; Caro, I. W.; Pandorfi, H.; Silva, I. J. O.; Moura, D. J. Zootecnia de precisão: análise de imagens no estudo do comportamento de frangos de corte em estresse térmico. Revista Brasileira de Engenharia Agrícola e Ambiental, v.9, n.1, p.115-119, 2005.

Sheppard, A.; Edge, S. Economic and operational impacts of the proposed EU directive laying down minimum standards for the protection of chickens kept for meat production. Exeter: Research undertaken for Defra by the University of Exeter Centre for Rural Research and ADAS, 2005. 246p.

Silva, M. A. N.; Hellmeister Filho, P.; Rosário, M. F.; Coelho, A. A. D.; Savino, V. J. M.; Garcia, A. A. F.; Silva, I. J. O.; Menten, J. F. M. Influência do sistema de criação sobre o desempenho, a condição fisiológica e o comportamento de linhagens de frango de corte. Revista Brasileira de Zootecnia, v.32, n.1, p.208-213, 2003.

Sundrum, A. Organic livestock farming - A critical review. Livestock Production Science, v.67, n.3, p.207-215, 2001.

Takahashi, S. E.; Mendes, A. A.; Saldanha, E. S. P. B.; Pizzolante, C. C.; Pelícia, K.; Garcia, R. G.; Paz, I. C. L. A.; Quinteiro, R. R. Efeito do sistema de criação sobre o desempenho e rendimento de carcaça de frangos de corte tipo colonial. Arquivo Brasileiro de Medicina Veterinária e. Zootecnia, v.58, n.4, p.624-632, 2006.

Yalcin, S.; Settar, P.; Ozkan, S.; Cahaner, A. Comparative evaluation of three commercial broiler stocks in hot versus temperate climates. Poultry Science, v.76, n.7, p.921-929, 1997.

Young, R. J. Environmental enrichment for captive animals. Oxford: Blackwell Science, 2003. 228p. 